\title{
Easier Access for General Aviation Pilots to Instrument Flight Rules Flying
}

\section{Iveta Kameníková ${ }^{\text {* }}$}

\author{
${ }^{1}$ Department of Air Transport, Faculty of Transportation Sciences, Czech Technical University in Prague, Prague, \\ Czech Republic \\ *Corresponding author: Czech Technical University in Prague, Faculty of Transportation Sciences, Department of Air \\ Transport, Horská 3, 12803 Prague, Czech Republic, Email: kamenikova@fd.cvut.cz
}

\begin{abstract}
To allow better acces for VFR pilots to hold IFR privileges, EASA introduced new pilot Qualification - Basic IR. This new qualification is porposed by EASA document NPA 2016-14, which introduces priviliges and repsonsibilities for this qualification. Basic IR is based mainly on existing license En-route IR but with signifcatn differences. Main difference is possibility to use basic IR even for 2D and 3D approaches. Even thought Basic IR is based on competency principles, it shall not be confused with competency based IR qualification, which holds differeNt privileges. With introduciton of Basic IR are connected several issues and problems which covered in this article. Every information in this article is referenced on NPA 2016-14.
\end{abstract}

\section{Keywords}

Approach procedures - Basic IR - General aviation - IFR flying — IR qualification

\section{Introduction}

The goal of the Agency's General Aviation Road Map is to work towards simpler, lighter and better rules for GA. During the 2014 EASA Safety Conference on General Aviation, the topic of 'easier access of GA pilots to IFR flying' was identified by the GA community as an important initiative to improve the safety and utility of GA flying. This was in response to the safety concerns and the views of the GA community that the current regulatory regime for many aspects of IFR flying should be made more proportionate [1].

With better access to IFR flying, GA pilots would be able to plan A-B flights with more confidence of safe completion. They would be less vulnerable to changing weather conditions and the associated risk of continuous visual flight rules (VFR) flights into instrument meteorological conditions (IMC) [2, 3]. As well as increasing the safety and resilience of GA flying, it will also reduce the complexity of longer flights, which often require extensive planning and contingency provisions to be executed under VFR. IFR flight planning for longer A-B flights is often more straightforward - thus encouraging pilots to conduct flights that they might otherwise have not attempted. This will bring safety and economic benefits.

\section{NPA 2016-14 Easier access for general aviation pilots to IFR flying}

To fulfil aforementioned EASA prepared document Notices of Proposed Amendment NPA 2016-14. The goal of the Agency's General Aviation Road Map is to work towards 
simpler, lighter and better rules for GA. During the 2014 EASA Safety Conference on General Aviation, the topic of 'easier access of GA pilots to IFR flying' was identified by the GA community as an important initiative to improve the safety and utility of GA flying. This was in response to the safety concerns and the views of the GA community that the current regulatory regime for many aspects of IFR flying should be made more proportionate.

With better access to IFR flying, GA pilots would be able to plan A-B flights with more confidence of safe completion. They would be less vulnerable to changing weather conditions and the associated risk of continuous visual flight rules (VFR) flights into instrument meteorological conditions (IMC). As well as increasing the safety and resilience of GA flying, it will also reduce the complexity of longer flights, which often require extensive planning and contingency provisions to be executed under VFR. IFR flight planning for longer A-B flights is often more straightforward - thus encouraging pilots to conduct flights that they might otherwise have not attempted. This will bring safety and economic benefits.

Based on questionnaires, expert meetings and conference outputs was decided that best way ho to fulfil these goals is to introduce new type of IR qualification. This new qualification is named Basic IR and has several important differences from IR.

\section{Basic IR}

The key principles for the BIR are as follows:

\section{- Training that is entirely competency-based}

There will be no minimum hours requirement set for the BIR. Instead, the TF analysed all the required competencies that a GA pilot would need for an IFR flight, and grouped them into three modules of training. Candidates will progress to the next module or skill test when ready to do so.

\section{- Training that is flexible}

The core module of instrument flying skills must always be completed first, and after having done so, the candidate may choose which further module to tackle next, within a timescale that suits them. This takes into account the fact that GA pilots may often not have the time or financial resources to commit to a more conventional full course of training towards the IR.

\section{- Focus on the practical needs of GA pilots}

Holders of the BIR should feel confident to use it to the full extent of its privileges. While IFR flight has many safety advantages, central to its philosophy is to assess the risks of a particular flight in a more systematic way. To this end, the training will be focused on the real-world instrument flying needs of GA pilots, with particular emphasis on practical application of threat and error management. This will ensure that the full safety and utility benefits of IFR flight are reaped.

\section{- High standards of training and testing}

Despite the focus on GA needs, practical training and testing standards will be similar to those of the current Part-FCL CB-IR and EIR, particularly with regard to interaction with other airspace users. It is very important that GA pilots flying under IFR have the required competencies for this.

Training is divided in 3 separate modules:

- Module 1 provides the foundation of instrument flying competencies. A course completion certificate will be issued after an acceptable standard has been reached and before the pilot is allowed to commence further training modules

- Module 2 introduce 2D and 3D instrument approach procedures such as non-directional radio beacon (NDB), instrument landing system (ILS), performance-based navigation (PBN) (for example, global navigation satellite system (GNSS), etc.), standard instrument arrival (STAR), and standard instrument departure (SID)

- Module 3 include en-route flight under IFR.

It will be up to the training organisation or instructor to determine whether the competencies have been assimilated to the required standard before progressing to the next module or skill test. This will allow candidates with a good aptitude to progress faster, while ensuring that slower-learning candidates progress only until they are ready.

As mentioned before, Module 1 is considered as core module and cannot be bypassed. After completion of Module 1 the student-pilot can decide which module he will pursue next.

\section{Privileges and limitations of BIR licence holders}

The BIR holders will be restricted to $200 \mathrm{ft}$ above the published minima on an approach procedure, down to a maximum of $500 \mathrm{ft}$ above ground level (AGL) for a 3D approach, or 600 $\mathrm{ft}$ AGL for a 2D approach. They will also be subject to an arrival and departure minima of $1500 \mathrm{~m}$ visibility and a cloud base of not less than $600 \mathrm{ft}$ or the published circling minimum applicable to the aeroplane category, whichever is greater.

And also the BIR will only be used for single-pilot, nonhigh-performance aircraft and may not be used for aircraft for which the relevant operational suitability data (OSD) has determined that an IR is required.

Other than the above limitations, the privileges will be the same as in Part-FCL CB-IR and EIR, with no restrictions on where the privileges may be used in terms of airspace or other factors.

The training under this new license will not be possible in new category of training organisation, the 'declared training organisation' (DTO), which was introduced by Annex VIII (Part-DTO) to Commission Regulation (EU) No 1178/2011. 
With existence of basic IR the agency of the opinion to remove En-rout IR (EIR) from legislative. There is not yet decided if current EIR license holders will forced to pursue new license or if there will some cross training. But because of relatively small number of EIR license holders it will be probably to left without any cross training, because Basic IR is competency based, so all skill from EIR shall be usable in basic IR.

The Agency is aware of the need to have the proposed new BIR appropriately integrated in the context of the current Part-FCL provisions for IFR flying qualifications. To that end, there should be a proportionate upgrade path from the BIR to the full IR privileges via the existing competency-based (CB) route.

\section{Theoretical knowledge}

Requirements, it is proposed that each training module is supported by an exam incorporating the relevant learning objectives, resulting in a total of three focused exams.

Learning objectives will not duplicate topics already examined at PPL level, but will focus only on objectives appropriate for the safe operation of GA aircraft in IMC or under IFR. The scope and depth of knowledge should be broadly similar to that required for the FAA IR.

The Agency wishes to make the exam process as straightforward as possible. The questions will have to be taken from the relevant areas of the European Central Question Bank (ECQB), otherwise the BIR would require entirely new questions, something that the Agency and the EASA Member States do not have the resources for. It is intended that EASA Member States shall adopt a secure process that would allow the exams to be conducted at training organisations equipped with the appropriate technology to meet the ECQB requirements.

With theoretical knowledge training is connected other important issue. The whole theoretical training syllabi is based on CBIR syllabi as published in AMC to PART-FCL. But CBIR theoretical training syllabi was already upgraded by another NPA. In NPA 2016-03 [4] EASA reintroduced changes in theoretical training of ATPL, CPL, IR and also CBIR.

Actual situation is that in NPA 2016-14 [5] is EASA proposing new license based on syllabus which was already replaced by newer one. Reference basic IR theoretical knowledge syllabus on older version of syllabus seems very unfortunate. Older syllabus is based on JAA learning objective (LO) from early 2000 so there are still LO like :

"State that there are two main GNSSs currently in existence, with a third one planned to be fully operational by 2011."

It is obviously old information which is not based in reality but what is more surprising that authors of NPA 2016-14 considered this LO as important and state that it shall be part of TK basic IR training.
Also part of the NPA describing parts of training could have been prepared more precisely. There are numbers of missing important information especially in connection with PBN operations. Also there several misprints like substitution of climb gradient for climate gradient etc. The training was prepared with mostly radio navigation in mind, but the current situation is that radio navigation is quickly forsaken in favour for PBN. The ration between radio navigation training and PBN training should be opposite, with favour for PBN.

Language proficiency was removed from this document to prevent English to be barrier for better IR usage in general aviation.

\section{Instructors}

Amending the relevant instructor ratings to accommodate the BIR will be delivered by Rulemaking Group for RMT.0596 . Main proposals are:

- All current instructors and examiners, who have the privilege to teach or examine for the IR, will also get the privilege to teach or examine for the BIR;

- An FI(A) holding a BIR, and having passed the instrument flying instructor (IRI) course, may teach for the BIR without being required to have completed 200 hours flight time under IFR; and

- An aeroplane flight examiner (FE(A)) may conduct skill tests for the initial issue, and for the revalidation or renewal of a BIR, provided they have 1000 hours flight time as pilot-in-command (PIC) on aeroplanes, including 250 hours instruction, and have the privilege to conduct instrument flying instruction; and

- An aeroplane class rating examiner $(\mathrm{CRE}(\mathrm{A}))$ may conduct revalidation or renewals of BIRs, provided they have 1000 hours flight time as pilot supervising (PS) on aeroplanes and have passed the IRI course.

\section{Conclusion}

Introduction of new Basic IR qualification is step towards simplify process of obtaining IR privileges for general aviation pilots. The proposed changes to PART-FCL which were introduced in NPA 2016-14 seem to be consistent with EASA approach to general aviation. It is unfortunate that NPA 2016-14 contains several aspects which are less than ideal. Especially not existing link between to NPA 2016-3 seems to be big step back. For aviation community is important that there is still possibility to address all issues with this NPA to EASA with CRT (comment response tool). CRT application for this NPA will be opened til 12th January 2017.

\section{References}

[1] Jakub Hospodka and Anna Polánecká. GNSS for VFR flights. In Proceedings of 19th International Conference 
Transport Means 2016, pages 555-558. Kauno technologijos universitetas (KTU), oct 2015.

[2] Marek Štumper, Jakub Kraus, and Dita Dudová. Safety assessment of various types of instrument approach. In Proc. of Zvyšovanie bezpečnosti a kvality v civilnom letectve 2016, pages 48-51. Technical University of Žilina, 2016. ISBN 978-80-554-1143-9. [in Czech].

[3] Jakub Kraus, Marek Štumper, and Petra Burjánková. Comparison of IFR to VFR, CBP and IFR Approach - What is the Best for Small Aerodrome. In Proc. of Aeronautika $X V$, pages 64-67. Lublin University of Technology, 2015. ISBN 978-83-7947-149-2.

[4] EASA. European aviation safety agency notice of proposed amendment 2016-3, 2016. URL https: //www.easa.europa.eu/document-library/ notices-of-proposed-amendment. [Online].

[5] EASA. European aviation safety agency notice of proposed amendment 2016-14, 2016. URL https: //www.easa.europa.eu/document-library/ notices-of-proposed-amendment. [Online]. 